\title{
Cervical Microglandular Polyp
}

National Cancer Institute

\section{Source}

National Cancer Institute. Cervical Microglandular Polyp. NCI Thesaurus. Code C6856.

A benign endocervical polypoid epithelial hyperplasia characterized by the presence of tightly packed glandular structures. It is usually seen in women on oral contraceptive therapy and during pregnancy. 